\title{
MENGEMBANGKAN POTENSI MASYARAKAT MELALUI KEGIATAN LITERASI YANG EFEKTIF DAN APLIKATIF DI DESA SUKAJADI
}

\author{
Leny Muniroh $^{1}$, Dede Suryana, Eko Budiarto ${ }^{2}$ \\ lenny@uika-bogor.ac.id \\ Dosen Fakultas Ekonomi ${ }^{1}$, Mahasiswa KKN Kelompok 45 Tahun $2017^{2}$
}

\begin{abstract}
ABSTRAK
Literasi secara etimologi berasal dari bahasa latin Littera yang memiliki pengertian melibatkan sistem tulisan yang menyertainya. Literasi adalah hak asasi manusia yang fundamental dan pondasi untuk belajar sepanjang hayat. Hal ini penting sepenuhnya untuk pembangunan sosial dan manusia dalam kemampuannya untuk mengubah kehidupan (UNESCO, 2015). Alberta (2009) Menurutnya, arti literasi bukan hanya sekedar kemampuan untuk membaca dan menulis namun menambah pengetahuan, keterampilan dan kemampuan yang dapat membuat seseorang memiliki kemampuan berpikir kritis, mampu memecahkan masalah dalam berbagai konteks, mampu berkomunikasi secara efektif dan mampu mengembangkan potensi dan berpartisipasi aktif dalam kehidupan bermasyarakat). National Literacy Forum (2014) Menyatakan bahwa ada empat cara yang harus dilakukan dalam membangun literasi yang universal yaitu: meningkatkan kemampuan bahasa sejak dini di rumah dan dalam pendidikan non formal, lebih mengefektifkan pembelajaran yang dapat menumbuhkan keterampilan membaca dan menulis di sekolah, adanya akses untuk membaca dan program yang membuat anak merasa senang melakukan kegiatan literasi, menciptakan kerjasama antara sekolah, lingkungan, keluarga dan lingkungan kerja untuk dapat mendukung budaya literasi. Oleh karna itu kami mencoba menerapkan konsep literasi dari para Ahli di dalam kegiatan kemasyarakatan khususnya diwilayah Desa Sukajadi Rw 05 Rt 01,02 dan 03 yang mana tingkat pendidikan masih belum merata.
\end{abstract}

Kata Kunci : Aplikatif, Efektif, Literasi, Masyarakat.

\section{PENDAHULUAN}

Secara letak geografis dan tipologi wilayah, daerah Desa Sukajadi memiliki luas 304,1Ha dan memiliki wilayah yang berdekatan dengan daerah-daerah lain diantaranya:

\begin{tabular}{|c|l|c|}
\hline No & Keterangan & Berbatasan \\
\hline 1 & Utara & Kecamatan Dramaga \\
\hline 2 & Selatan & Desa Tamansari \\
\hline 3 & Barat & Kecamatan Tenjolaya \\
\hline 4 & Timur & Desa Sukajaya \\
\hline
\end{tabular}

Desa Sukajadi memiliki lahan pertanian dan perkebunan yang potensial untuk menghasilkan produk tanaman pangan (padi dan jagung) perkebunan (cabai, tomat, timun, pisang dan lain sebagainya) lahan yang terdapat di Desa Sukajadi merupakan lahan kering yang bagus untuk perkebunan dan pertanian.

Disamping dalam hal pertanian dan perkebunan Desa Sukajadi pun mempunyai potensi untuk bidang peternakan karena pemilik desa sukajadi memiliki daerah 
yang cukup luas dan memiliki lahan yang hijau.

Kampung Sinarwangi Desa Sukajadi Kecamatan Tamansari adalah desa yang memiliki potensi alam yang indah tetapi masih memiliki beberapa permasalahan dalam beberapa bidang diantaranya bidang pendidikan, kesehatan dan lingkungan dan ekonomi.

\section{Pendidikan}

\begin{tabular}{|c|l|c|}
\hline No & Tingkat Pendidikan & Jumlah \\
\hline 1 & SD & 2581 \\
\hline 2 & SMP & 427 \\
\hline 3 & SMA & 228 \\
\hline 4 & Akademik (D1-D3) & 193 \\
\hline 5 & Sarjana (S1-S3) & 22 \\
\hline
\end{tabular}

Jumlah Penduduk

\begin{tabular}{|c|l|c|}
\hline No & Jenis Kelamin & Jumlah \\
\hline 1 & Laki-Laki & 3.856 \\
\hline 2 & Perempuan & 3.927 \\
\hline 3 & Kepala Keluarga & 2.267 \\
\hline
\end{tabular}

Dari data profil kelurahan diatas diperoleh tingkat kepadatan penduduk rata - rata untuk Desa Sukajadi adalah 707,545 jiwa/km.
Secara umum kondisi masyarakat Desa Sukajadi Kp. Sinarwangi RW 05 yang telah kami lakukan observasi bahwa masyarakat Kampung Sinarwangi RW

05 cenderung lebih mudah bersosialisasi dan menerima pendatang baru dengan tangan terbuka contoh seperti kamui yang akan melakukan KKN Terintegrasi masyarakat menyambut dengan tangan terbuka dan apresiasi yang spontan dari masyarakat sekitar.

Melihat respon masyarakat yang baik maka dari itu ketika kami melakukan program kerja kemasyarakatan, orangorang sekitar pun antusias dengan giatnya mengikuti program-program yang kami selenggarakan yang tentunya untuk maanfaat daerah Kp. Sinarwangi Rw 05.Jadi dapat kami ambil kesimpulan bahwasanya kondisi Masyarakat Desa Sukajadi Kp. Sinarwangi Rw 05 terlihat baik, bersabahat dan menerima orangorang pendatang dengan tangan yang terbuka tanpa adanya konflik dari berbagai pihak. 


\section{METODE PENGABDIAN}

Tahapan pelaksanaan pada kegiatan ini, dapat dilihat pada bagan dibawah ini:

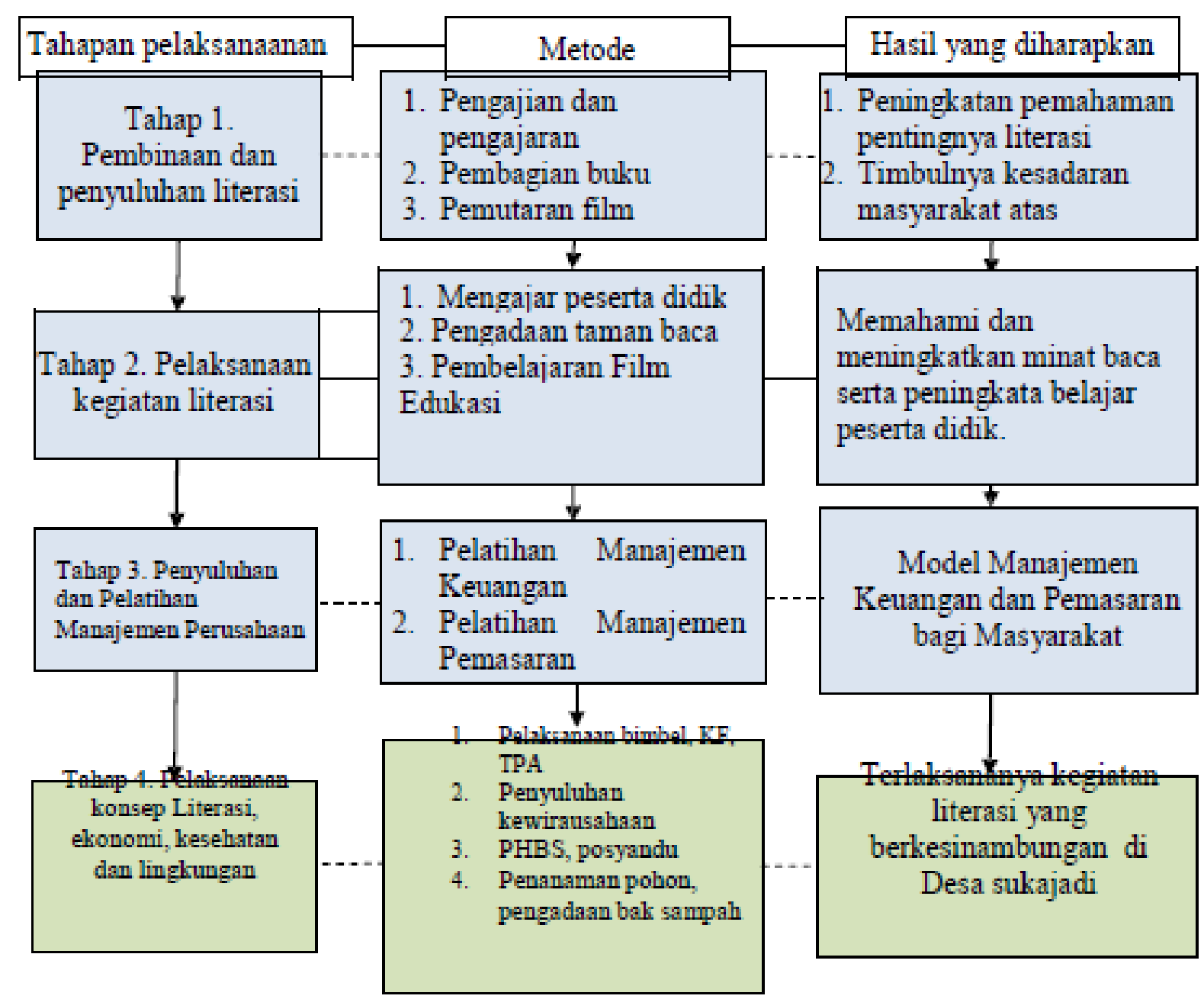


Jadwal Kegiatan

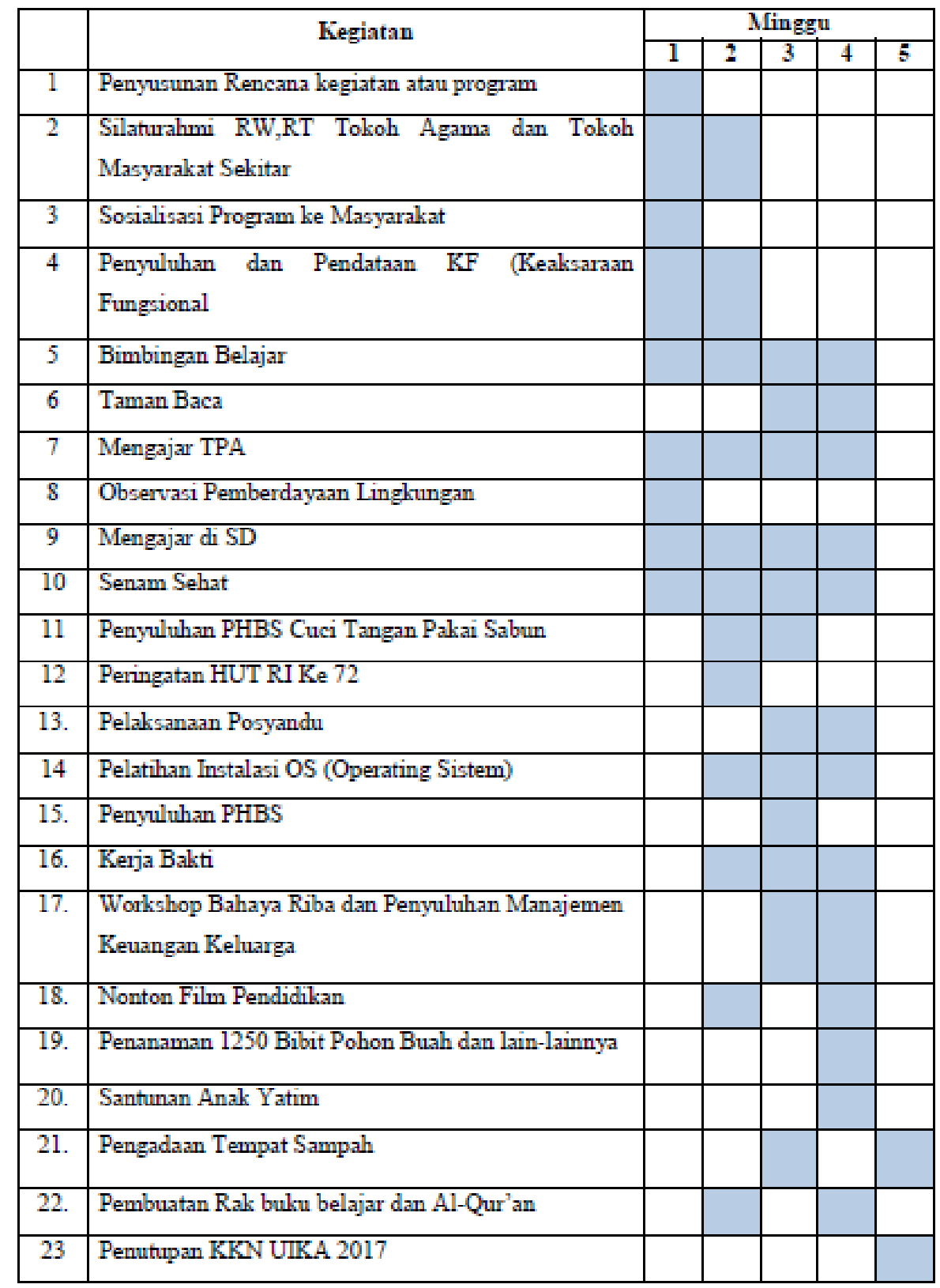

\section{Metode Pendekatan}

Pendekatan yang digunakan dalam kegiatan ini adalah:

1. Pendekatan religius, yaitu pendekatan yang menggunakan nilai-nilai agama sebagai basis kegiatan. Pendekatan ini sangat penting karena permasalahan pemahaman radikalisme dalam masyarakat sangat dipengaruhi oleh faktor keimanan, pengalaman keagamaan, rasa tanggungjawab dan pengetahuan.
2. Pendekatan organisasi, yaitu pendekatan dimana seluruh kegiatan diorganisir oleh Kelompok 45 KKN UIKA Bogor dan pemuda pemudi atau karang taruna desa Sukajadi Bogor. Hal ini sesuai dengan hasil penelitian Bahari (2010) dimana dia menemukan bahwa keterlibatan organisasi mempunyai pengaruh langsung terhadap toleransi.

3. Pendekatan kekerabatan, artinya bahwa pembinaan yang dilakukan senantiasa dikaitkan dalam rangka membangun 
kekerabatan antar jama'ah yang semakin memudar.

4. Pendekatan berdasarkan karakter masyarakat, yakni pembinaan yang dilakukan akan disesuaikan dengan karakter masyarakat. Joyce dan Weil (1996) mengungkapkan bahwa model pendidikan yang relevan dengan perilaku sosial dan nilai adalah dengan banyak memberikan permainan peran. Hal ini dilakukan untuk memberi pengalaman riil kepada peserta didik tentang sesuatu yang dilakukan atau dirasakan oleh orang lain. Memang, dalam prakteknya, tidak seluruh aspek harus menggunakan permainan ini. Dalam beberapa hal, terdapat kegiatankegiatan yang hanya golongan tertentu untuk melakukannya. Sejalan dengan konsep Joyce dan Weil, cooperative learning yang digagas Slavin (2005) dapat digunakan untuk membangun kesadaran toleransi masyarakat. Hal ini karena penekanan dari konsep pendidikan ini adalah kerjasama yang merupakan urat nadi toleransi. Dengan demikian, model pendidikan yang akan dibangun menggunakan dua konsep utama yaitu role playing model dan cooperative learning model.

\section{Partisipasi Masyarakat dalam Pelaksanaan Program}

Partisipasi masyarakat yang dilakukan dalam kegiatan ini adalah sebagai berikut:

1. Mempersiapkan masyarakat mulai dari orang tua hingga anak anak yang bersedia mengikuti pembinaan program literasi dan mempersiapkan tempat untuk pembinaan dan pelatihan.

2. Mempersiapkan tempat untuk pembinaan literasi / pendidikan
3. Pelaksana kegiatan pembinaan, terutama tentang pendidikan.

4. Bersama-sama dengan Tim Pengusul melakukan monitoring pelaksanaan pembinaan dan pelatihan.

\section{Langkah Evaluasi}

Evaluasi yang akan dilakukan terdiri dari:

1. Evaluasi proses, yang terkait dengan perencanaan, pelaksanaan dan monitoring kegiatan. Evaluasi proses akan dilakukan setiap pekan bersama dengan masyarakat.

2. Evaluasi hasil, yang akan dilaksanakan setelah kegiatan dilaksanakan.

Evaluasi hasil ditujukan untuk menguji pemahaman masyarakat tentang pentingnya pendidikan.

3. Evaluasi dampak, yang akan dilakukan 6 (enam) bulan setelah pelaksanaan pembinaan. Evaluasi dampak diarahkan untuk melihat efektivitas model pembinaan dan keberlangsungan industri rumah tangga.

\section{REALISASI PROGRAM}

\section{Program Bidang Pendidikan}

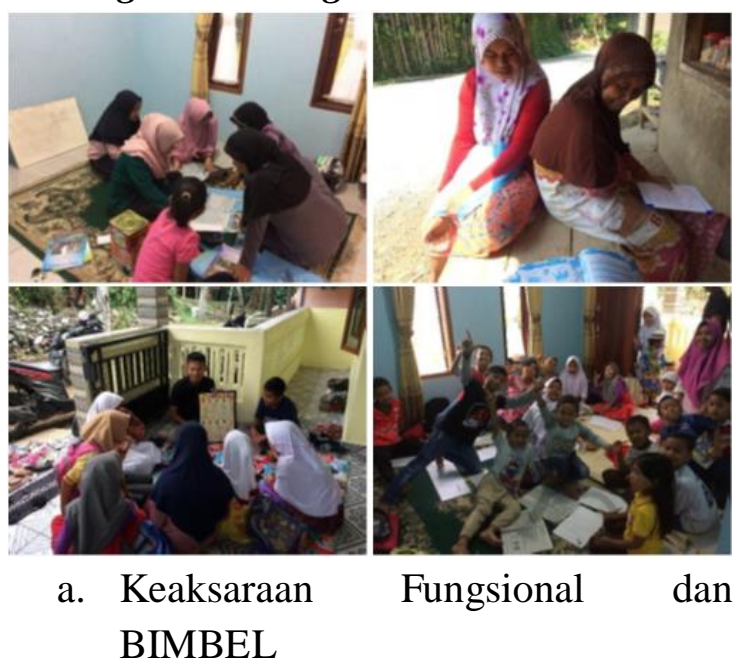




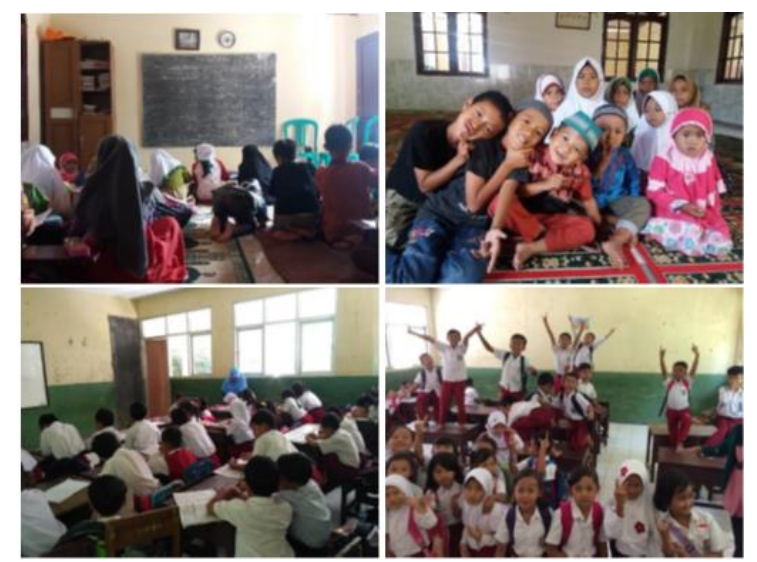

b. Ikut Mengajar SD dan TPQ

\section{Program Bidang Lingkungan}

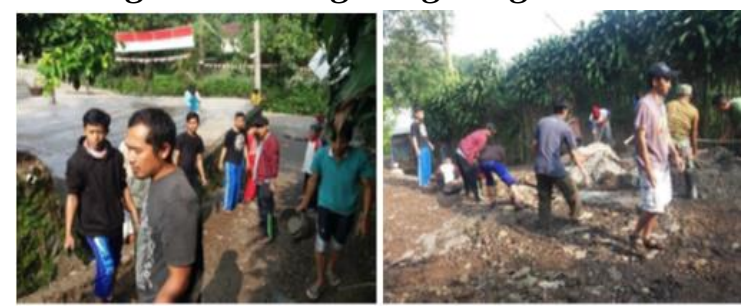

a. Kerja bakti

b. Penanaman bibit pohon kayu dan buah

\section{Program Bidang Ekonomi}

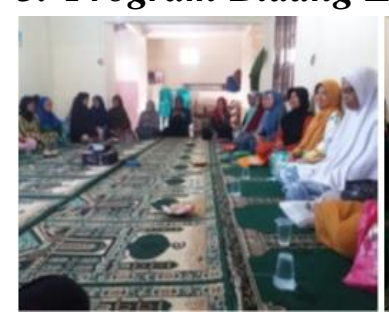

a. Penyuluhan berwirausaha

b. Penyuluhan ekonomi keluarga

\section{Program Bidang Kesehatan}

a. Posyandu (Pos Pelayanan Terpadu)

b. Edukasi kewaspadaan anak terhadap orang lain.

c. Senam pagi bersama

d. Penyuluhan Cuci tangan pada anak

\section{KESIMPULAN}

a. Masyarakat desa sukajadi RW 05 sangat antusias dengan program kegiatan yang dijalankan.

b. Masyarakat desa sukajadi sangat antusias dengan program kegiatan dalam bidang pendidikan.

c. Masyarakat sangat membantu dalam melaksanakan segala kegiatan sehingga dapat berjalan dengan lancar.

d. Kesadaran berwirausaha warga masih kurang, banyak warga yang kerja keluarga daerah padahal desa Sukajadi adalah desa wisata yang mana dapat dikembangkan potensi usaha di daerah Sukajadi.

e. Masalah kebersihan menjadi masalah yang harus segera ditanggulangi karena dilingkungan sekitar Rw 05 belum ada tempat sampah dan TPU sehingga warga adayang membuang sampah sembarangan.

f. Antusiasme yang tinggi dari anak-anak dalam mengikuti pelajaran

g. Banyaknya jumlah anak-anak di wilayah Rw 05 dapat menjadi potensi pengembangan SDM yang lebih berkualitas dalam bidang pendidikan oleh karena itu membutuhkan dukungan sarana dan prasarana dari pihak masyarkat dan pihak pemerintah untuk lebih ditingkatkan

\section{SARAN}

Berdasarkan kesimpulan yang telah dipaparkan maka penulis mengajukan rekomendasi yang dipandang berguna dan yang dapat mempertimbangkan agar dapat meningkatkan kompetensi masyarakat pada bidang literasi khususnya dan bidang 
lainnya seperti bidang ekonomi, kesehatan dan lingkungan diantaranya:

\section{Bidang Pendidikan}

a. SDN

Kepada pihak sekolah
GDN
menindaklanjuti permasalahan sarana
dan prasarana sekolah untuk lebih
ditibgkatkan engan baik seperti
pengadaan meja dan kursi belajar,
instalasi listrik, serta pengadaan kamar
mandi bagi siswa dan guru agar lebih
pantas dan lebih layak

b. TPA

Kepada pemerintah khususnya kementrian agama lebih memperhatikan guru-guru atau tenaga pengajar dalam bidang agama di kampung atau di desa terutama dalam meningkan kesejehteraan tenaga pengajar karena seperti kita ketahui tenaga pengjar agama di desa atau kampung kurang diperhatikan

c. Keaksaraan fungsional

Kepada warga belajar khususnya ibu-ibu yang masih produktif untuk lebih berminat belajar.

\section{Bidang Kesehatan}

Pelayanan kesehatan harus lebih ditingkatkan terutama dalam fasilitas pelayanan dan peralatan medis mengingat bahwasanya di daerah sukajasdi akses kerumah sakit lumayan jauh.

\section{Bidang Ekonomi}

Mengingat desa Sukajadi memiliki potensi alam yang makmur maka bidang usaha yang cocok untuk masyarakat desa Sukajadi adalah dalam bidang barang dan jasa khususnya dalam objek wisata.

\section{Bidang Lingkungan}

Kepada pemerintah daerah untuk lebih memperhatikan masalah kebersihan terutama di daerah-daerah yang jauh dari kota seperti desa Sukajadi dan kepada masyarakat untuk lebih peduli dan memperhatikan masalah kebersihan terutama jangan membuang sampah sembarangan.

Kepada masyarakat setempat diharapkan untuk menajaga dan melestarikan pepohonan karena ketika di musim hujan pepohonan berfungsi untuk menyerap air dan ketika di musim kemarau tetap tersedianya cadangan air. 


\section{REFERENSI}

Administrasi Profil Desa Sukajadi

Alberta (2009). the meaning of literacy is not just the ability to read and write

Bahari. (2010). Toleransi Beragama Mahasiswa (Studi tentang Pengaruh Kepribadian, Keterlibatan Organisasi, Hasil Belajar Pendidikan Agama, dan Lingkungan Pendidikan terhadap Toleransi Mahasiswa Berbeda Agama pada 7 Perguruan Tinggi Umum Negeri. Jakarta: Kementerian Agama RI Badan Litbang dan Diklat Puslitbang Kehidupan Keagamaan.

http://www.indonesiastudent.com/pengerti an-literasi-menurut-para-ahli/

Joyce, Bruce dan Weil, Marsha. (1996). Models of Teaching. Boston: Allyn and Bacon

National Literacy Forum (2014). four ways to do in building literacy

Petunjuk Pelaksanaan KKN Tematik Terintegrasi 2017 Universitas Ibn Khaldun Bogor

Slavin, R.E. (2005). Cooperative learning: theory, research and practice. London: Allyn and Bacon.

UNESCO (2005). Literacy is a fundamental human right and the foundation for lifelong learning 